\title{
Jordi Monés (2011) La pedagogia catalana al segle xx. Els seus referents. Lleida. Ed. Pagès/ IEC. 544pp.
}

La relació entre educació i societat és una línia de recerca bàsica per a comprendre els fils conductors de les polítiques pedagògiques d'acord amb les necessitats de la majoria social i determinades per la cultura política hegemònica. De fet, la identitat (conflictiva) entre 'Estat' i pensament pedagògic és un binomi predominant per a comprendre les (dis)continuïtats de qualsevol tradició de les doctrines educatives. Aquest context, però, cobra especial rellevància a l'època contemporània, com bé ho indica Pere Solà Gussinyer en els darrers quatre capítols de la recerca Educació $i$ societat a Catalunya (Ed. Eumo/ Ed. Pàgès, Lleida, 2011), estudi que té per objecte sintetitzar l'evolució de les institucions educatives d'ençà de la feudalitat fins als nostres dies. Amb tot, calia una reflexió de conjunt sobre el que es concep com a segle de l'educació, el segle vintè. És en aquest sentit que cal valorar l'assoliment -el seu primer balanç general, que amb una certa actualització o addenda caldria reeditar, fou El pensament escolar i la renovació pedagògica a Catalunya (1833-1938) [1977]- de Jordi Monés amb La pedagogia catalana al segle xx. Els seus referents

El plantejament politicoideològic -en ciències socials no existeix cap concepció interpretativa "neutral"- que articula tot l'assaig de Monés és d'utilitat per a comprendre els models de pensament i pràctica pedagògics propis articulats en la contemporaneïtat. Així, del text es desprèn l'interrogant de si és plantejable una pedagogia catalana satèl-lit respecte de la legitimada per l'Estat espanyol; o, per contra, les concepcions i aplicacions formatives contemporànies són molt més deutores dels models internacionals. En aquest sentit, una de les conclusions de l'assaig que ens ocupa és que la proposta pedagògica regeneracionista espanyola del noucents -Institucion Libre de Enseñanza (ILE)- té poc pes específic en l'àmbit educatiu del Principat i més, en canvi, al País Valencià. Aquest fet té a veure amb la respectiva capacitat de nacionalització del moviment de construcció nacional? És una hipòtesi que potser caldria aprofundir, més si hom té en compte, com s'esmenta en el text, la política contra l'ensenyament en català a l'ensenyament públic promoguda pel Partit Radical lerrouxista el 1916. De tota manera el fet nacional és una variable, no pas casual, perquè una hipòtesi que subjau al treball que comentem és la relació entre pedagogia i construcció nacional, relació que cal tenir molt en compte dins la trajectòria de recerca de Jordi Monés pel que fa a l'estudi sobre el conflicte lingüístic (aspecte vigent) en el panorama educatiu dels Països Catalans. 
D'altra banda, una segona variable a destacar en la reflexió que tractem és la recepció de corrents de modernitat pedagògica sota diversos codis metodològics. En aquest sentit, cal remarcar l'influx del moviment de l'Escola Nova, que sota el context de la Il-lustració i del Romanticisme (categories no pas inequívocament antinòmiques), basteix els fonaments del que es defineix com a pedagogia activa. És clar, però, que aquesta tipologia, com deixa entreveure l'autor, és massa genèrica a l'hora de plantejar un model intel-lectual i polític transfomador. I precisament aquest extrem constitueix un node significatiu de la pedagogia (catalana) del segle xx: reformisme o revolució? No es tracta, però, d'una hipòtesi reduccionista, esbiaixada, gratuïta. Seguint l'assaig que ens ocupa, la concepció de l'Escola Nova plantejaria una metodologia orientada a la construcció social d'una tipologia d'antropologia pedagògica a fi d'assolir una societat ètica, una collectivitat del benestar, però sense qüestionar l'estatus sociopolític dominant. La motivació que aconduiria aquest enfocament seria modificar hàbits, actituds i valors individuals per a construir una societat més justa i acabar qüestionament l'argumentació rousseauniana de la perversió de l'home en establir-se el procés de socialització.

En canvi, l'opció revolucionària es tradueix pedagògicament al Principat en la recepció de models entre lliurepensadors, anarquistes i comunistes. Independentment de l'abast social assolit per aquests programes, el que resta clar és que el país fou receptiu a plantejaments alternatius respecte del model reformista burgès.

En efecte, fos I'Escola Moderna de Ferrer i Guàrdia, I'ateneisme que promulgà una pedagogia no formalitzada adreçada a les classes subalternes, i les anàlisis comunistes pel que fa a un model que tenia com a referent la revolució soviètica dels anys vint, el que es desprèn del text de Monés és que la resposta al noucentisme pedagògic -que tingué una certa continuïtat en la primera etapa de la República (1931-1936)- sorgeix de la limitada hegemonia en el temps polític del Front d'Esquerres (1936-1939).

Aquest fet és explicat a partir de la ruptura nacionalsindicalista i nacionalcatòlica com a conseqüència de l'ocupació politicomilitar franquista. "1939" significa un 'abans' i un 'després' en el panorama cultural, educatiu. Un 'abans', perquè el Nuevo Estado francofalangista vol anul.lar tota aportació que havia posat al mapa pedagògic internacional Catalunya, sobretot a través de la política pedagògica de la Mancomunitat (1914-1924). I un 'després' perquè el relleu generacional de nous ensenyants havia constituït el Moviment de Renovació Pedagògica articulat a partir de la segona meitat dels anys cinquanta. Aquest assoliment organitzatiu recuperava les tradicions modernitzadores d'Alexandre Galí, de Rosa Sensat i es feia ressò del cooperativisme escolar de Célestine Freinet. Amb tot, el que es pot plantejar del context indicat és que existeixen uns paral-lelismes, que caldria apronfudir comparativament, entre els anys trenta i els anys seixanta. D'una banda, hi havia una necessitat de trobar referents ocultats -reprimits- pel franquisme que sevissin de marcs de coneixement per a concretar propostes de futur en una conjuntura de nou tipus d'industrialització i de model urbanístic metropolità entre 1959 i 1973, que 
suposà un determinant canvi social. De l'altra, l'organització associativa -Escoles d'Estiu- impulsava xarxes que posaven en pràctica -des de la base-, models d'ensenyament cooperatius -escoles actives- adscrits a la realitat nacional.

La segona part de la síntesi de Monés abasta, doncs, tot aquest context complex, fluctuant, bastit de retrocessos, opressió, però també d'innovació. De fet, si es fes un estudi destallat de la constitució de les escoles primàries basades en la coeducació, laïcitat i ensenyament vehiculat en la llengua nacional, ens adonaríem que el moviment de recuperació de l'escola nova aportava qualitativamant un altra concepció pedagògica.

Ara bé, aquest ampli cicle de resposta al model oficialista -entre l'esperit de La Hispanidad i la tecnocràcia opusdeista- resta, després de la lectura del text de Jordi Monés, en una cruilla. I es pot pensar des d'aquest dubte, perquè el debat actual educatiu és susceptible de ser plantejat -més enllà de les lleis d'ensenyament i els plans d'estudis "reformadors" els anys setanta- en el context sociopolític i intel-lectual caracteritzat pel procés d'unificació de mercats a Europa en aquests darrers vint anys. Però aquest aspecte -una síntesi crítica dels corrents pedagògics contemporanis que ens interpel-la davant la fallida del neoliberalisme educatiu- demana un altre estudi continuador respecte del que ens ocupa. Amb tot, cal destacar la conclusiò a què arriba Monés pel que fa a la manca de correspondència entre la lluita dels ensenyants als anys seixanta i l'encertat qüestionament de la capacitat política de la Generalitat per a dur a terme una veritable política pedagògica sense dependència, fet que caldria plantejar "sense prejudicis politicosocials" (p. 495).

Metodològicament l'estudi que comentem planteja la dificultat de delimitació entre la història de l'educació i la historicitat dels plantejaments teòrics. Així, la teoria de l'educació és un reflex de la filosofia social (tota pedagogia és filosofia de l'educació). Aquest aspecte és d'especial interès per a situar la història de l'educació en l'àmbit de les ciències socials i no reduir, per tant, el fet educatiu a una modalitat estrictament tècnica, sinó que, com es deriva d'aquest treball, la fusió entre concepció antropològica (si es vol neoidealista) -Joaquim Xirau- i reflexió sobre la pràctica pedagògica -Seminari de Pedagogia a la Universitat de Barcelona als anys trentaconstitueix una unitat metodològica, car un fet comú a ambdós procediments és la voluntat integradora de la pedagogia en el pensament contemporani. No d'una altra manera cal explicar, per exemple, el ressò de models epistemològics europeus dels anys vint -Giovani Gentile- en els Quaderns d'Estudi, publicació del Consell de Pedagogia de la Mancomunitat editada entre octubre de 1915 i març de 1924. Igualment cal destacar, en aquest sentit, la recepció de propostes de la República de Weimar (1919-1933) en models de formació dels anys trenta.

El darrer apartat del volum -que, tal vegada podria haver estat deixatat en el decurs de la recerca- és dedicat a l'educació de gènere. Aquest bloc representa una estat de la qüestió sobre els darrers cent anys de l'accés a la formació de la dona, l'accés al treball i la qüestió implicita d'aquesta lluita amb la tradició cultural de les classes subalternes. 
El tractat de Monés suposa una reflexió que aborda una temàtica central de l'evolució pedagògica nacional: com cal entendre la internacionalització a través de la projecció desacomplexada -sense pensar-nos com a subsistema nacionalitari- de la pròpia identitat intel-lectual i la comparació dels assoliments institucionals respecte d'altres països i llur concepció de modernitat.

Xavier Ferré Trill, professor lector del Departament de Pedagogia de la Universitat Rovira i Virgili. 